\title{
Prevalence of nutritional anaemia in pediatric age group a cross sectional study
}

\author{
Naik R.R.K. ${ }^{1}$, Venkatesha K.R. ${ }^{2}$ \\ ${ }^{1}$ Dr. R. Ravikumar Naik, Professor, ${ }^{2}$ Dr. Venkatesha K.R, Associate Professor; both authors are affiliated with \\ Department of Paediatrics, Sapthagiri Institute of Medical Sciences, Bengaluru, Karnataka, India.
}

Corresponding Author: Dr. Venkatesha K.R., Associate Professor, No-138, $5^{\text {th }}$ Cross, East of NGEF layout, Kasthuri Nagar, Bengaluru-43, India.

\begin{abstract}
Introduction: The term 'nutritional anaemia' encompasses all pathological conditions in which the blood hemoglobin concentration drops to an abnormally low level, due to a deficiency in one or several nutrients. The main nutrients involved in the synthesis of hemoglobin are iron, folic acid, and vitamin $\mathrm{B}_{12}$. Objective: To study the prevalence of nutritional anaemia in paediatric age group. Methodology: A cross sectional study was undertaken in children with nutritional anaemia attending department of paediatrics, tertiary care hospital, Bangalore during the period January 2016 to December 2016. Results: Out of the 167 children studied, 86 children belonged to the age group of 6 year to 14 year and 59 children belong to 6 month to 6 year age group and 22 children belongs to 14 year to 18 year age group. Majority were males and accounted for 88 of the subjects with females accounting for 79. Majority (64 cases) belonged to class iv (upper lower), with 50 cases belonging to class iii (lower middle) socio-economic status according to modified kuppuswamy classification. Majority were vegetarians constituting 101 cases and the rest 66 cases belong to nonvegetarians. Conclusion: Anaemia needs to be immediately attended to. Strategies and documents endorse this need. WHO / UNICEF / UNU strongly advocate that when there is a prevalence of anaemia above $40 \%$, a universal supplementation is required and it is not cost-effective to screen children for anaemia.
\end{abstract}

Keywords: Anaemia, Children, Hemoglobin

\section{Introduction}

The term 'nutritional anaemia' encompasses all pathological conditions in which the blood hemoglobin concentration drops to an abnormally low level, due to a deficiency in one or several nutrients.

The main nutrients involved in the synthesis of hemoglobin are iron, folic acid, and vitamin $\mathrm{B}_{12}$. In public health terms, iron deficiency is by far the first cause of nutritional anaemia worldwide. Folic acid deficiency is less widespread and is often observed with iron deficiency. Vitamin $\mathrm{B}_{12}$ deficiency is far rarer. Therefore, the focus in this article is on Iron-deficiency anaemia in children.

Anaemia is defined as a reduction of the hemoglobin concentration or $\mathrm{RBC}$ volume below the range of values occurring in healthy persons [1].

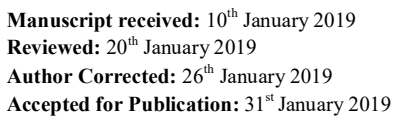

Hemoglobin thresholds to define anaemia

1. Children between 6 months to 6 years - less than 11 $\mathrm{gm} \%$ of hemoglobin

2. Children between 6 years to 14 years - less than $12 \mathrm{gm} \%$ of hemoglobin.

3. Adolescent male - less than $13 \mathrm{gm} \%$ of hemoglobin.

4. Adolescent female-Less than $12 \mathrm{gm} \%$ of hemoglobin

It is useful to consider iron deficiency as existing in three functionally distinct stages of severity.

1. Stage of storage iron deficiency: Exist when iron reserves are smaller than normal but has a full complement of hemoglobin and other functional iron proteins. This stage is characterized by a decrease in serum ferritin in the absence of other biochemical evidence of iron deficiency in enzymes.

2. Stage of iron limited erythropoiesis: is said to exist when the iron supply is inadequate to support basal erythropoiesis. Hemoglobin level will be in the lower range of normal, serum iron is decreased, Total iron binding capacity is increased, saturation of transferrin 
with iron is decreased and free erythrocyte protoporphyrin is increased.

3. Stage of iron deficiency anaemia: there is a decrease in Hemoglobin concentration along with progressive microcytosis and hypochromia.

It is well established that iron deficiency is a systemic disorder involving multiple systems rather than a purely hematological condition associated with anaemia. The early phases of iron deficiency anaemia are not associated with clearly recognizable signs or symptoms and its development is slow and insidious. Nonspecific symptoms include pallor, fatigability, irritability, anorexia, weakness, decreased activity, palpitations, dizziness, breathlessness and headache. When anaemia develops rapidly breathlessness, tachycardia, dizziness and fatigue are prominent features. When anaemia is chronic, only moderate dyspnea or palpitation occurs. When severe prolonged anaemia occurs, hyperdynamic cardiac failure may supervene, with edema, and even ascites. Heart murmurs are a common cardiac sign associated with anaemia. They are systolic and best heard in the pulmonic area Gallop rhythms may be detected [2].

A variety of behavioural disturbances have been observed in iron-deficient children. They include irritable and disruptive behaviours have short attention spans and lack of interest in their surroundings. Neurological development in infants and scholastic performance in older children are impaired. An attention deficit was the fundamental abnormality in most [3].

Epithelial tissue changes Iron-deficient patients are characterized by defective structure or function of epithelial tissue. Especially affected are the nails, tongue, mouth and stomach.

Finger nails may become brittle, fragile or longitudinally ridged. More typical are thinning,

\section{Original Research Article}

flattening and finally spoon shaped nails. Peripheral smear blood picture shows anisocytes and poikilocytes apart from microcytic and hypochromic red cells. Anisopoikilocytosis is an important early sign in iron deficiency. Presence of hypochromic red cells in peripheral smear is a good indicator of iron deficiency, but few other conditions, which give rise to a hypochromic microcytic picture needs to be differentiated from iron deficiency, like anaemia of chronic diseases, thalassemia, sideroblastic anaemia and lead poisoning [4].

Mean corpuscular volume (MCV), mean corpuscular hemoglobin $(\mathrm{MCH})$ are reduced whereas mean corpuscular hemoglobin concentration (MCHC) is reduced in long standing or severe anaemia [5].

The average MCV is $74 \mathrm{fl}$ (range 53-93 $\mathrm{fl}$ ), $\mathrm{MCHC}$ is $28 \mathrm{gm} / \mathrm{dl}$ (range $22-31 \mathrm{gm} / \mathrm{dl}$ ) and $\mathrm{MCH}$ is $20 \mathrm{pg}$ (range 14-29 pg). The degree of change in the red cell indices is related in part to the duration and in part to the severity of anaemia.

Tests for iron deficiency include: the serum ferritin, serum iron binding capacity (transferrin saturation) and the erythrocyte protoporphyrin.

\section{Objective}

To study the prevalence of nutritional anaemia in paediatric age group

\section{Methodology}

Place of study: Sapthagiri Institute of Medical Sciences, Bengaluru

Study duration: January 2016 to December 2016.

Type of study: A Cross Sectional Study

Sampling methods: stratified random sampling

Inclusion criteria: Children with nutritional anaemia attending Department of Paediatrics

Exclusion criteria: Children with congenital disease.

\section{Results}

Table-1: Age and sex wise distribution of cases

\begin{tabular}{|c|c|c|c|}
\hline Age group & Male & Female & Total \\
\hline 6 month -6 year & 31 & 28 & 59 \\
\hline 6 year -14 year & 45 & 41 & 86 \\
\hline 14 year -18 year & 12 & 10 & 22 \\
\hline Total & $\mathbf{8 8}$ & $\mathbf{7 9}$ & $\mathbf{1 6 7}$ \\
\hline
\end{tabular}

Out of the 167 children studied, 86 children belonged to the age group of 6 year to 14 year and59 children belong to 6 month to 6 year age group and 22 children belongs to 14 year to 18 year age group. Out of the 167 children studied, majority were males and accounted for 88 of the subjects with females accounting for 79 . 
Table-2: Socio economic status wise distribution of cases

\begin{tabular}{|c|c|}
\hline Socio-Economic status & Number of Cases \\
\hline Class I & 12 \\
\hline Class II & 21 \\
\hline Class III & 50 \\
\hline Class IV & 64 \\
\hline Class V & 20 \\
\hline Total & $\mathbf{1 6 7}$ \\
\hline
\end{tabular}

Out of 167 children studied, majority (64 cases) belonged to class IV (upper lower), with 50 cases belonging to class III (lower middle) socio-economic status according to Modified Kuppuswamy classification.

Table-3: Dietary Habits wise distribution of cases

\begin{tabular}{|c|c|}
\hline Dietary habit & Number of cases \\
\hline Vegetarian & 101 \\
\hline Non-vegetarian & 66 \\
\hline Total & $\mathbf{1 6 7}$ \\
\hline
\end{tabular}

Majority were vegetarians constituting 101 cases andthe rest 66 cases belong tonon-vegetarians.

Table-4: Clinical manifestations

\begin{tabular}{|c|c|}
\hline Symptoms & Number of cases \\
\hline Pallor & 111 \\
\hline Bald tongue & 21 \\
\hline Platynchia & 45 \\
\hline Murmur & 11 \\
\hline
\end{tabular}

Out of 167 cases, pallor was the predominant clinical manifestation followed by platynchia.

Table-5: Classification of Anemia

\begin{tabular}{|c|c|}
\hline Type of Anaemia & Number of cases \\
\hline Mild anaemia & 11 \\
\hline Moderate anaemia & 36 \\
\hline Severe anaemia & 20 \\
\hline Normal & 100 \\
\hline
\end{tabular}

Out of 167 children studied, 11 cases had mild Anemia (Hb- 10-12 gm/dl) and 36 cases had moderate anaemia (Hb- 7-10 $\mathrm{gm} / \mathrm{dl}$ ) and 20 cases had severe anaemia.

\section{Discussion}

Out of the 167 children studied, 86 children belonged to the age group of 6 year to 14 year and 59 children belong to 6 months to 6 year age group and 22 children belongs to 14 year to 18 year age group. Majority were males and accounted for 88 of the subjects with females accounting for 79 . Majority (64 cases) belonged to class IV (upper lower), with 50 cases belonging to class III (lower middle) socio-economic status according to Modified Kuppuswamy classification. Majority were vegetarians constituting 101 cases andthe rest 66 cases belong to non-vegetarians. Pallor was the predominant clinical manifestation followed by platynchia.
11 cases had mild anemia (Hb- 10-12 gm/dl) and 36 cases had moderate anaemia ( $\mathrm{Hb}-7-10 \mathrm{gm} / \mathrm{dl})$ and 20 cases had severe anaemia.Rachana Bhoite, Uma Iyer et al (2011) studied the magnitude of malnutrition and anaemia in rural school children of Vadodara. 3010 rural school children from 1 to 7 standard. Malnutrition was highly prevalent with $70 \%$ of children being underweight. Stunting was evident in $32.4 \%$ of girls and $30.8 \%$ boys. The prevalence of severe underweight children was $37 \%$ by CDC standards while it was $27 \%$ by WHO 2007 standards. Clinical signs and symptoms of various micronutrient deficiencies like Iron (33.5\%), vitamin A (8.12\%) were also seen. 
Dietary pattern showed that majority of thechildren skipped the breakfast and consumption of MDM was intermittent. Prevalence of anaemia was $73 \%$ and the severity was more in undernourished children. Sensitivity of $64 \%$ and specificity of $44 \%$ was obtained for correlation between haemoglobin and clinical signs and symptoms of iron deficiency anaemia [6].

Sudha Gandhi et al (2009-2010) studied the prevalence of anaemia in school children of Kattankulathur, Tamil Nadu. A total of 900 children in the age group of 8-16 years were included in this study. Parental consent was obtained in the written format. Blood was collected by finger prick and the haemoglobin was determined by cyanmethemoglobin method.

A pre-planned questionnaire was used to collect the health details of the children. The children were grouped according to age. Prevalence of anaemia as per the World Health Organization recommended cut off value of haemoglobin, among these children was $52.88 \%$. The frequency of the prevalence of anaemia was significantly higher amongst girls as compared to boys. Results of the study population reveal that $52.88 \%$ were anaemic, girls (67.77\%) were $32.2 \%$ higher than the boys (35.55\%) and anaemic children were underweight [7].

Severe anaemia is a major cause of sickness and death in African children, yet the causes of anaemia in this population have been inadequately studied. We conducted a case-control study of 381 preschool children with severe anaemia (hemoglobin concentration, $<5.0 \mathrm{~g}$ per $\mathrm{dl}$ ) and 757 preschool children without severe anaemia in urban and rural settings in Malawi. Causal factors previously associated with severe anaemia were studied.

The data were examined by multivariate analysis and structural equation modeling. Bacteremia (adjusted odds ratio, 5.3; 95\% confidence interval [CI], 2.6 to 10.9 ), malaria (adjusted odds ratio, 2.3; 95\% CI, 1.6 to 3.3), hookworm (adjusted odds ratio, 4.8; 95\% CI, 2.0 to 11.8), human immunodeficiency virus infection (adjusted odds ratio, 2.0; 95\% CI, 1.0 to 3.8 ), the G6PD (-202/-376) genetic disorder (adjusted odds ratio, 2.4; 95\% CI, 1.3 to 4.4 ), vitamin A deficiency (adjusted odds ratio, $2.8 ; 95 \% \mathrm{CI}, 1.3$ to 5.8 ), and vitamin $\mathrm{B} 12$ deficiency (adjusted odds ratio, 2.2; 95\% CI, 1.4 to 3.6 ) were associated with severe anaemia. Folate deficiency, sickle cell disease, and laboratory signs of an abnormal inflammatory response were uncommon. Iron deficiency was not prevalent in case patients (adjusted odds ratio, $0.37 ; 95 \% \mathrm{CI}, 0.22$ to 0.60 ) and was negatively associated with bacteremia. Malaria was associated with severe anaemia in the urban site (with seasonal transmission) but not in the rural site (where malaria was holoendemic). Seventy-six percent of hookworm infections were found in children less than 2 years of age. There are multiple causes of severe anaemia in Malawian preschool children, but folate and iron deficiencies are not prominent among them. Even in the presence of malaria parasites, additional or alternative causes of severe anaemia should be considered [8].

Anaemia has been a big problem in India and the National Family Health Survey (NFHS) III data showed the prevalence of anaemia among children less than five years of age to be around $70 \%$. When we look at the data for anaemia prevalence among children under three years of age, it jumps to $79 \%$ and this is five percent more than the NFHS II survey done six years prior to the NFHS III survey, which was done in $2005-2006$.

However, it is noteworthy that there has been a slight reduction in the prevalence of severe anaemia, while there has been an increase in the overall anaemia, over the last seven years $[9,10]$.

About 93 million children - eight percent of the total population of India estimated at 116 million in the year 2009 - are below the age of three. Nearly 73 million children below the age of three (79\%) suffer from varying degrees of anaemia, and over 50 million suffer from moderate-to-severe anaemia. These figures of anemia prevalence, when compared to the current data and studies done in the 1970s and 1980s by the Indian Council of Medical Research (ICMR), do not show any difference, indicating the persistence of India's anaemia epidemic, believed largely to be due to iron deficiency $[11,12]$.

Studies done prior to 1985 , in India, gave an average prevalence rate of $68 \%$ in pre-school children. The prevalence in different studies varied from 48 to $95 \%$, placing all the states of India under the high magnitude category. However, this data is for children under five years of age and a specific age group of children under two years is not studied separately, where the prevalence is expected to be higher. Based on studies by the National Nutrition Monitoring Bureau, anaemia prevalence among children one to five years of age is around $66 \%$, with a wide range of 33 to $93 \%$ across different states. Kotecha and Kotecha studied anemia prevalence in children under three years of age in Vadodara urban slum and found anemia prevalence to be as high as $91 \%[13,14,15,16]$. 


\section{Conclusion}

Anaemia needs to be immediately attended to. Strategies and documents endorse this need. WHO / UNICEF / UNU strongly advocate that when there is a prevalence of anemia above $40 \%$, a universal supplementation is required and it is not cost-effective to screen children for anemia.

However, clinically speaking, many technical experts believe that to differentiate severe anemia, a screening is desirable and that is reflected in India's Tenth Fiveyear Plan's nutritional goals, where all children are recommended to be screened.

\section{What this study adds to existing knowledge?}

This is in light of the fact that iron deficiency is almost universal when dealing with this magnitude of anaemia.

Funding: Nil, Conflict of interest: None initiated, Perission from IRB: Yes

\section{References}

1. Norma BL. Nelson textbook of Pediatrics. 16th ed. Saunders;2011.

2. Argano BJ. Phonocardiographic findings in anemia. Chest. 1971 Dec; 60(6):599-601.

3. Cook JD, Lynch SR. The liabilities of iron deficiency. Blood. 1986 Oct;68(4):803-9.

4. Bessman JD, Feinstein DI. Quantitative anisocytosis as a discriminant between iron deficiency and thalassemia minor. Blood. 1979 Feb; 53 (2):288-93.

5. Conrad ME, Crosby WH. The natural history of iron deficiency induced by phlebotomy. Blood. 1962 Aug; 20:173-85.

6. Rachana B, Uma I. Magnitude of Malnutrition and Iron Deficiency Anemia among Rural School Children: An Appraisal ASIAN J. EXP. BIOL. SCI-2011;2 (2): 34-6.
7. Sudha GB, Sivapatnam S, Ebenezer WE, Prema A. Prevalence of anemia in the school children of Kattankulathur, Tamil Nadu, India. www.ijnpnd.com/ article.asp?issn=2231-0738; year=2011.

8. Calis JC, Phiri KS, Faragher EB, et al. Severe anemia in Malawian children. N Engl J Med. 2008 Feb 28;358(9):888-99. doi: 10.1056/NEJMoa072727.

9. National Family Health Survey for India conducted by. Mumbai, India: International Institute for Population Science. N.F.H.S: $3^{\text {rd }}$ ed; 2006.

10. National Family Health Survey for India conducted by. Mumbay, India: International Institute for Population Science. N.F.H.S: $2^{\text {nd }}$ ed; 1999.

11. Vijayaraghavan K, Brahmam GN, Nair KM, et al. Evaluation of national nutritional anemia prophylaxis programme. Indian J Pediatr. 1990;57(2):183-90.

12. Community studies using common salt fortified with Iron. Annual report. Hyderabad: National Institute of Nutrition. $2^{\text {nd }}$ ed; 1978.

13. Rao KV, Radhaiah G, Raju SV. Association of growth status and the prevalence of anaemia in preschool children. Indian J Med Res. 1980 Feb;71:23746.

14. Singla PN, Gupta HP, Ahuja C, et al. Deficiency anaemias in preschool children--estimation of prevalence based on response to haematinic supplementation. J Trop Pediatr. 1982 Apr; 28(2):77-80.

15. National Nutrition Monitoring Bureau: Prevalence of Micronutrient Deficiencies: NNMB Technical Report No. 22, National Institute of Nutrition;2003.

16. Kotecha IS, Kotecha PV. Prevalence of Irondeficiency anemia in children 6-35 months of age in urban slum areas served by 0 integrated child development service project in Vadodara city: Department of Preventive and Social Medicine, Medical College Vadodara;2005.

\section{How to cite this article?}

Naik R.R.K., Venkatesha K.R. Prevalence of nutritional anaemia in pediatric age group a cross sectional study. Int J Pediatr Res. 2019;6 (01):17-21.doi:10.17511/ijpr.2019.i01.03 